\title{
A prospective study of acute cerebrovascular disease in the community: the Oxfordshire Community Stroke Project, 1981-86
}

\author{
Charles P Warlow
}

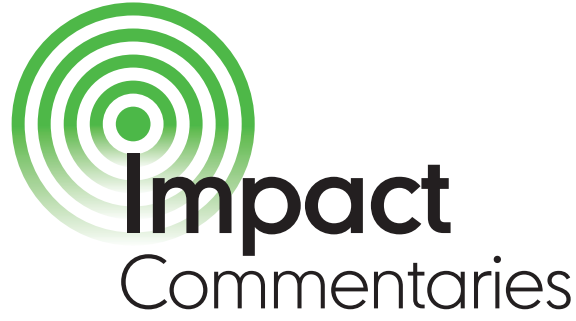

Counting strokes in Oxfordshire: epidemiological rigour and neurological obsessiveness by Charles Warlow

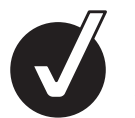

Citations are a slippery metric. Slippery to measure because citations from government EDITOR'S papers, and books, are seldom CHOICE counted. Slippery to interpret too. Are many citations because the paper was scientifically groundbreaking like the letter to Nature describing the structure of DNA? Or because it described a trial which changed the way large numbers of people should be treated-for example, by coiling rather than clipping to secure ruptured intracranial aneurysms? Or because the paper described a score which we all now use, like the Glasgow Coma Score, or a technique which changed the face of clinical neurology, like CT brain scanning? Or is it because the paper has become notorious like the Wakefield paper in the Lancet which set off the MMR scare, or the too big to be true association between the XMRV virus and myalgic encephalomyelitis in Science?

I don't know why our paper describing the final overall results of the Oxfordshire Community Stroke Project has been cited

Correspondence to Professor C Warlow, Department of Clinical Neurosciences, Western General Hospital,

Crewe Rd, Edinburgh EH9 1TE, UK;

charles.warlow@ed.ac.uk
Title: A PROSPECTIVE STUDY OF ACUTE CEREBROVASCULAR DISEASE IN THE COMMUNITY: THE OXFORDSHIRE COMMUNITY STROKE PROJECT, 1981-86 ${ }^{1}$

Authors: Bamford J, Sandercock P, Dennis M, Burn J, Warlow C

Published: 1988

so often, indeed not being an obsessive about these things I have no idea how many times it has been cited (the modern equivalent is to obsess about your internet 'hits'). Maybe the earlier papers from the Oxfordshire Community Stroke Project published in the $B M J$ have been cited more often. Unfortunately, citations are the basis of the so called 'Impact Factor' which is such a poor surrogate for what has really made an impact. Assessing impact is far more subjective, and open to bias, particularly if done by one of the authors.

With that caveat, I would suggest we had at least three impacts. Firstly, we showed it was possible to measure stroke incidence as well as outcome reasonably accurately in a population and distinguish between infarct and haemorrhage with CT scanning in most patients, with a surprisingly high post mortem rate of $37 \%$. Secondly, we implicitly laid down the methodological ground rules for this sort of study. Thirdly, it provided a baseline for the OXVASC study some 20 years later which showed that stroke incidence was declining, at least in Oxfordshire, perhaps because of better risk factor control (luckily the definition of stroke had not changed over this period, unlike that of myocardial infarction). ${ }^{2}$

However, the paper was far from perfect, even then. The numbers were too small to accurately determine the incidence of intracerebral and subarachnoid haemorrhage, and we must have over-diagnosed ischaemic rather than haemorrhagic stroke for scanning too late. Furthermore, as ever in these sort of studies, we would not have been accurate in the very elderly, witnessed by the unlikely fall in intracranial haemorrhage over the age of 85 years. In fact, I doubt if it will ever be possible to do the absolutely perfect stroke incidence study based on a defined population, with large enough numbers, and accurate classification of stroke type and subtype in every case.

Why did we send the paper to JNNP and not a journal with a higher citation ratio (also known as impact factor)? In those easier days we were not flagellated by our universities to chase publication in high citation ratio journals-we simply thought that as clinical researchers reporting findings particularly relevant to the UK, we should publish in a well regarded clinical journal which UK neurologists were most likely to read.

Competing interests None.

Provenance and peer review Commissioned; not externally peer reviewed.

Accepted 7 September 2011

Published Online First 6 January 2012

J Neurol Neurosurg Psychiatry 2012;83:579. doi:10.1136/jnnp-2011-301381

\section{REFERENCE}

1. Bamford J, Sandercock P, Dennis, et al. A prospective study of acute cerebrovascular disease in the community: the Oxfordshire Community Stroke Project 1981-86. 1. Methodology, demography and incident cases of first-ever stroke. J Neurol Neurosurg Psychiatry 1988;51:1373-80.

2. Rothwell PM, Coull AJ, Giles MF, et al; for the Oxford Vascular Study. Change in stroke incidence, mortality, case-fatality, severity, and risk factors in Oxforshire, UK from 1981-2004 (Oxford Vascular Study). Lancet 2004;363:1925-33. 